\title{
Aprendamos a aprender Medicina
}
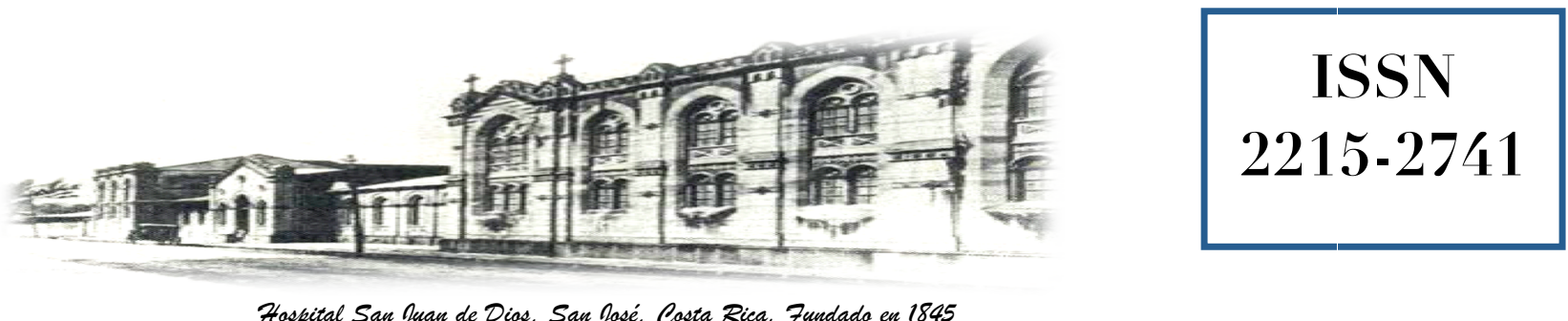

Haspital San quan de Dias. San Yosé. Casta Rica. Fundada en 1845

Recibido: $\quad 20 / 11 / 2014$

Aceptado: $\quad 19 / 02 / 2014$

Luis Fernando Briceño Rodríguez ${ }^{1}$

${ }^{1}$ Ex-Miembro Sección de Medicina - Hospital San Juan de Dios. Profesor Asociado Universidad de Costa Rica (pensionado). Correo electrónico: 1briceno@racsa.co.cr

El aprendizaje de Medicina es un proceso continuo que se inicia desde nuestra época de estudiantes, a nivel universitario, y que finaliza con el ocaso de nuestras vidas. Nunca dejamos de aprender y comprender algo nuevo.

Acá empieza el dilema: información versus formación.

Son múltiples las fuentes de información: cientos de libros, miles de revistas y millones de artículos científicos; más la facilidad de acceso a la información digital vía Internet.

No obstante, ayer, hoy y siempre, la principal y más importante fuente del conocimiento médico son nuestros propios pacientes.

Algunos estudiantes de Medicina, tanto de pregrado, grado y posgrado, consideran que esta bella profesión se aprende tan sólo estando escuchando una clase o conferencia magistral, y se olvidan lo indispensable que es el autodidactismo, el deseo investigativo de explorar el por qué de las cosas.
Al finalizar los años de carrera universitaria y posteriormente los años de un posgrado médico, no hemos terminado aún; más bien, es el inicio de nuestra profesión. La cantidad de información actual es tal, que día con día debemos seguir forjando nuestro conocimiento, pero más aún, nuestra formación.

Es en este punto, donde esa principal fuente de aprendizaje es nuestro paciente. Así es, nuestra formación está "al pie de la cama, al lado de de nuestros enfermos.

Sin embargo, no basta la información y el conocimiento de las enfermedades, es comprender integralmente al enfermo, es entender el por qué de cada síntoma y signo que de él obtenemos; es entender el por qué de cada hecho; es saber interpretar cada dato de laboratorio y gabinete presentes.

Muchos estudiantes y colegas buscan al paciente en el libro, pero esto no es correcto; se debe buscar el libro en el paciente. 
No es necesario únicamente citar el último artículo de la última revista; sino más importante, entender lo que está pasando en nuestro paciente. Para esto, es fundamental conocer adecuadamente la estructura y función del cuerpo humano, para poder llevar a cabo un adecuado entendimiento de la enfermedad.

Debemos profundizar en la búsqueda de cada detalle y tratar de explicarlo, de integrarlo. No debemos ser conformistas al comparar datos obtenidos de un caso con otro, debemos siempre considerar la individualidad biológica, ya que un paciente no es igual a otro. Tampoco debemos ser conformistas al comparar lo nuestro únicamente con la información foránea y "buscar que calce como si fuera una postal", debemos aprender a comprender, a razonar, a vivir la incertidumbre, lo bello de la duda; aprender a vivir la Medicina.

Debemos aprender a buscar nuestra propia realidad, el comportamiento de nuestras enfermedades y nuestros enfermos. Debemos aprender a investigar, a perder el temor a no encontrar al paciente en el libro; a perder el temor a decir "no sé", ya que muchas enfermedades las vamos conociendo con el tiempo.

Es acá donde debemos buscar un equilibrio entre información y formación. La primera, fundamental en nuestra actualización, en la incorporación de nuevos conceptos a nuestro conocimiento; la segunda, fundamental en nuestro entendimiento, en nuestra actitud y capacidad de ayuda a nuestros semejantes, nuestros pacientes.

Así es, aprendamos a aprender.

Basado, actualizado y modificado de:

Briceño R, LF. El aprendizaje de la Medicina.

Práctica Médica 1996; 1 (3): 2.

(Autorización por Dr. Chi Hao Chen Ku - Cuerpo Editorial

Revista Práctica Médica 1996) 